\title{
Proteinase-related broad-spectrum inhibitory activity among group-A streptococci
}

\author{
W. L. HYNES and J. R. TAGG
}

Department of Microbiology, University of Otago, Dunedin, New Zealand

\begin{abstract}
Summary. Some $10 \%$ of group-A streptococci have inhibitory activity against all nine strains (eight of them streptococci) in a set of indicators in an inhibitor-production typing (P-typing) scheme. This activity was associated with the concurrent synthesis of cell-associated proteinase by the streptococcal strain. Inhibitor production was prevented either by incubation of the test strain in conditions inimical to proeteinase production, e.g., at low temperature and alkaline $p \mathbf{H}$, or by addition to the medium of substances, such as glucose, iodoacetic acid, lincomycin, Congo red or trypan blue, that had an anti-proteinase effect. Inhibitory activity was not detectable in liquid cultures, but freeze-thaw extracts of cultures of group-A streptococcus strain A1013 on Gibco Columbia Agar Base (Gibco Diagnostics, Madison, WI, USA) had some inhibitory activity. The inhibitor was concentrated and partially purified, and the active agent was shown to be a high-mol.-wt cationic protein which was bactericidal for various bacteria in the logarithmic growth phase, including the homologous producer strain.
\end{abstract}

\section{Introduction}

Tagg and Bannister (1979) described a typing scheme for streptococci based in part on the production by the test strains of inhibitory activity against a set of nine indicator strains. Streptococci inhibiting the growth of all nine indicators were referred to in code form as members of productiontype (P-type) 777. Inhibitory activity of this type seems confined to strains of Lancefield group-A streptococci, some $10 \%$ of which belong to this $\mathrm{P}$ type (Tagg and Bannister, 1979; Hynes and Tagg, 1985a). Among the group-A streptococci, P-type777 activity appears to be associated with strains of only a restricted range of $\mathrm{M}$ serotypes, 14 having thus far been identified (Hynes and Tagg, 1985a).

In the original description of P-type-777 activity (Tagg and Bannister, 1979) two unusual characteristics were noted: (1) there was a specific requirement for human blood to be present in the typing medium; and (2) self-inhibition could be demonstrated when a P-type- 777 strain was used both as producer and indicator. The apparent dependence on human blood prompted speculation that the inhibitory activity might be a determinant of virulence for man (Tagg and Bannister, 1979), but the

Received 10 Dec. 1985; revised version accepted 23 Apr. 1986. biological significance of the production of an autoinhibitory substance was uncertain (Hynes and Tagg, 1985a). These workers also confirmed that human blood was necessary for P-type- 777 activity on typing medium prepared from Difco Columbia Blood Agar Base (CBAB; Difco Laboratories, Detroit, MI), but when Gibco Columbia Agar Base (CAB; Gibco Diagnostics, Madison, WI) was used, the requirement for blood was far less stringent; on this medium, ovine, bovine or equine blood sufficed and a small proportion of P-type-777 strains exhibited this type of inhibitory activity in the absence of blood.

All P-type-777 strains form proteinase (Hynes and Tagg, 1985a) and Gibco CAB is a particularly good medium for the production of group-A streptococcal proteinase (Hynes and Tagg, 1985b). Some group-A streptococci produce sufficient proteinase on Gibco CAB-based typing medium to bring about the proteolytic conversion of haemoglobin to the toxic derivative, haematin. This usually results in inhibition of indicators $\mathrm{I} 2$ and $\mathrm{I} 7$, a pattern referred to in code form as P-type 204 (Hynes and Tagg, 1986). We now report an investigation of the relationship between proteinase production and the broader-spectrum inhibitory activity of group-A streptococci of P-type-777. 


\section{Materials and methods}

\section{Bacterial strains}

The set of nine standard indicators (I1-I9) used for $P$ typing comprised eight streptococci and a Micrococcus luteus strain (I1), which has previously been referred to as a coagulase-negative staphylococcus (Tagg and Bannister, 1979). Six representative P-type-777 strains were described by Hynes and Tagg (1985a): 79-012 (M-type 2), 156 (M-type 12), A1013 (M-type 28), M60 (M-type 60), M28689 (M-type 75) and M25, which was previously referred to as strain 100 (M-type 25).

Derivatives of strain M25, apparently deficient in the production of streptolysin S, proteinase or P-type-777 inhibitory activity were obtained by either nitrosoguanidine mutagenesis (Cleary et al., 1975) or insertional inactivation by means of transposon Tn916 (Nida and Cleary, 1983). Streptolysin S-negative mutants were detected by plating treated cultures on to blood agar, proteinase-deficient derivatives were identified on Gibco CAB plus skim milk (see below) and $\mathbf{P}$-type-777-negativemutants by stab-inoculation of individual colonies into the typing medium, with seeding of the indicator lawn (16) deferred until after the stab cultures had been grown and the surface of the medium prepared by removal of the macroscopic bacterial growth and sterilisation with chloroform vapour (see below). Nitrosoguanidine-derived mutants used in the present study were negative for inhibitor (no. M25-3I), streptolysin S (no. M25-2H) or proteinase (no. M25-1P). The Tn916-related mutants were no. M25-Tn3 (inhibitor negative) and no. M25-Tnl (streptolysin-S negative).

Tests for inhibitor production. The successive stages of the standard P-typing procedure were performed as described by Tagg and Bannister (1979): streaking of the potentially inhibiting strain on a plate of the typing medium (Difco CBAB plus human blood 5\% v/v); incubating the plate aerobically at $32^{\circ} \mathrm{C}$ for $18 \mathrm{~h}$; scraping off the visible growth, exposing to choloform vapour and subsequent aeration; cross-streaking with Todd-Hewittbroth (THB; Difco) cultures $\left(37^{\circ} \mathrm{C}, 18 \mathrm{~h}\right)$ of the nine standard indicator strains; incubating the plates again aerobically at $32^{\circ} \mathrm{C}$ for $18 \mathrm{~h}$; inspecting the plates for inhibition of the growth of the indicators. This was recorded in code form by considering the nine indicators as three triplets in the order $11,12,13 ; 14,15,16 ; 17,18,19$ in each of which inhibition was scored as $4,2,1$.

Various modifications of this typing procedure were at times used in this study. Anaerobic incubation was in an atmosphere of $\mathrm{N}_{2} 85 \%, \mathrm{H}_{2} 10 \%$ and $\mathrm{CO}_{2} 5 \%$ in an anaerobic glove-box. An atmosphere of $\mathrm{CO}_{2} 5 \%$ in air was provided by a $\mathrm{CO}_{2}$ incubator.

Defibrinated sheep blood ( $5 \% \mathrm{v} / \mathrm{v}$; Laboratory Services Ltd, Auckland) sometimes replaced human blood; in some experiments the test medium contained no blood supplement. Gibco CAB and Blood Agar Base (Oxoid) were tried in place of Difco CBAB. The individual components of Gibco CAB were made available by the manufacturer, enabling altered formulations of the medium to be made, based on deletion of one or more of the constituents. Various additions were made to the standard human-blood-containing Gibco CAB medium: calcium carbonate $0.5 \% \mathrm{w} / \mathrm{v}$; MOPS (3[N-morpholino] propane sulphonic acid) buffer $0.1 \mathrm{M}(p \mathrm{H} 7.5$ or $p \mathrm{H} \mathrm{6.8);}$ glucose $0.05-0.5 \% \mathrm{w} / \mathrm{v}$; iodoacetic acid $0.00005 \mathrm{M}$; lincomycin $0.1 \mathrm{~g} / \mathrm{L}$ (Lincocin; Upjohn Co.); trypan blue $2 \mathrm{~g} / \mathrm{L}$ (Sigma) and Congo red $2 \mathrm{~g} / \mathrm{L}$ (Sigma).

\section{Local changes in the $p H$ of the medium}

These were measured by means of a Model 9210 Combination Surface $p \mathrm{H}$ Electrode (Broadly James Corp., Santa Anna, CA, USA), which was applied to the surface of the medium underlying the streak of streptococcal growth immediately after this had been removed with the edge of a glass slide.

\section{Assay of inhibitory activity}

A well-diffusion method was used (Hynes and Tagg, 1985a). Samples $(100 \mu \mathrm{l})$ of serial two-fold dilutions of inhibitor-containing fluids were added to 7 -mm-diameter wells in the assay medium and allowed to absorb. The surface of the medium was sterilised by exposure to chloroform vapour for $30 \mathrm{~min}$ before being swabbed evenly with the appropriate indicator from an overnight THB culture. After incubation for $18 \mathrm{~h}$ at $37^{\circ} \mathrm{C}$, the inhibitor titre was recorded as the highest dilution that gave definite inhibition of the growth of the indicator lawn and was expressed as an arbitrary unit (AU). The medium used for assay of P-type-777 preparations was Gibco CAB plus human blood. Assessment of the inhibitory activity of streptococcal proteinase was on Gibco CAB medium. Indicator Il was used as the standard strain in comparisons of the P-type-777 inhibitory activity in different preparations.

\section{Proteinase production}

This was detected by making stab inoculations into Gibco CAB plus skim milk (Difco) $1.5 \% \mathrm{w} / \mathrm{v}$ (Hynes and Tagg, 1985b); with proteinase-positive strains an opaque halo of precipitated casein developed around the site of the stab. Proteinase activity in liquid preparations was assayed by the use of hide-powder azure (Sigma) as described by Hynes and Tagg (1985b). For streptococci grown on solid media, cell-associated activity was detected similarily on growth that had been scraped from the surface of lawn cultures and resuspended in $1 \mathrm{ml}$ of physiological saline, and extracellular activity on the liquor extracted from the agar by freezing and thawing. Purified streptococcal proteinase, generously provided by Dr S. D. Elliott (Cambridge University) was used as a control.

\section{Concentration and purification of the inhibitory agent.}

The liquid media tested for inhibitor production 
included THB, Tryptic Soy Broth, Brain Heart Infusion (all from Difco), APT Broth (BBL, Division of Becton, Dickinson and Co., Baltimore, MD, USA) and the liquid equivalent of Gibco CAB, which was prepared from the individual components of this medium.

The solid medium from which inhibitory extracts were obtained was Gibco CAB medium. Plates of this were seeded by means of cotton swabs charged with cells from cultures $\left(37^{\circ} \mathrm{C}, 18 \mathrm{~h}\right)$ on Gibco CAB medium. After incubation at $32^{\circ} \mathrm{C}$ for $18 \mathrm{~h}$ the contents of a batch of plates $(2-3 \mathrm{~L})$ were removed to a bag of cotton gauze. This was frozen at $-70^{\circ} \mathrm{C}$ and later allowed to thaw while the bag was suspended over a beaker. The crude extract obtained by this procedure was clarified by centrifugation and solid ammonium sulphate was added to $60 \%$ saturation at $4{ }^{\circ} \mathrm{C}$. The precipitate was collected and redissolved in $0.1 \mathrm{~m}$ phosphate buffer $(p \mathrm{H} \mathrm{7.0)}$ to one-tenth of the original extract-volume and then dialysed against the same buffer to yield the concentrated crude inhibitor preparation. Samples $(3 \mathrm{ml})$ of this were fractionated on a column $(1 \times 48 \mathrm{~cm})$ of Sephadex G-100, equilibrated with $0.1 \mathrm{M}$ phosphate buffer $(p \mathrm{H} \mathrm{7.0)}$. The void volume was determined with Blue Dextran (Pharmacia, Uppsala, Sweden). The individual 3-ml fractions were assayed for inhibitor and the active fractions were combined to yield the partially purified inhibitor. DEAE Sephadex (Sigma) was equilibrated with $0.01 \mathrm{M}$ Tris buffer at $p \mathrm{H} 8.0$ and used to prepare columns $(1 \times 5 \mathrm{~cm})$. Concentrated crude inhibitor preparations dialysed against this same buffer were applied as samples and eluted with a linear $\mathrm{NaCl}$ gradient.

\section{Properties of the inhibitory material}

Ammonium sulphate-concentrated crude inhibitor preparations that had been heated at $80^{\circ} \mathrm{C}$ for $30 \mathrm{~min}$ to inactivate other streptococcal products were sterilised by filtration through a $0 \cdot 45-\mu \mathrm{m}$ membrane (Millipore Corp., Bedford, MA). The effect of $p \mathrm{H}$ and heating, and of various chemical and enzymic treatments, was tested by the well-diffusion method (Johnson et al., 1979). Their ability to kill or inhibit the growth of the indicator strains and their effects on the morphological appearance of sensitive bacteria were investigated essentially as described by Tagg et al. (1973). An equal volume of a 1 in 100 THB dilution of a 4-h THB culture of the test strain and of the inhibitor preparation (titre 4) were mixed and incubated at $37^{\circ} \mathrm{C}$. The viability of the culture was assessed at 1 -h intervals up to $4 \mathrm{~h}$ by obtaining samples, diluting in phosphate-buffered saline, plating known volumes on to Gibco CAB plus human blood and determining the number of $\mathrm{cfu} / \mathrm{ml}$. Optical density readings of control and test cell suspensions were made at $660 \mathrm{~nm}$.

\section{Results}

The effect of test conditions on P-type-777 inhibitory activity

The inhibitory activity of the six representative $P$ - type-777 strains in the standard test conditions was compared with that in tests in which either the composition of the typing medium or the conditions of incubation were modified (table I). Incubation for a minimum of $12 \mathrm{~h}$ was necessary for production of detectable levels of inhibitory activity; incubation beyond the usual period of $18 \mathrm{~h}$ did not seem to affect the degree of subsequent inhibition of the indicators. The temperature of incubation was important; all strains produced considerably less activity at $25^{\circ} \mathrm{C}$ than at $32^{\circ} \mathrm{C}$ and most strains showed diminished activity at $37^{\circ} \mathrm{C}$. The atmosphere of incubation had little effect on inhibitory activity. Anaerobic incubation led to a characteristic brown discoloration of the medium, an effect attributable to the low $p \mathrm{H}$ value $(c .5 .5)$ in such cultures; increased buffering by the inclusion of calcium carbonate $0.5 \% \mathrm{w} / \mathrm{v}$ in the typing medium reduced the magnitude of the $p \mathrm{H}$ change and the degree of inhibition of the indicators remained similar to that produced on aerobic incubation.

If Oxoid Blood Agar Base was substituted for Difco CBAB in the standard, blood-containing typing medium there was little inhibitory activity, but Gibco CAB seemed to be at least as effective as the Difco base in the presence of blood. Omission of human blood from the Difco medium abolished inhibitory activity, and its replacement by ovine blood did little to restore this. Sheep plasma appeared to contain a factor that interfered with the production of inhibitor; this was produced on Difco base supplemented with $5 \% \mathrm{v} / \mathrm{v}$ of equal parts of washed sheep RBC and human plasma but not with a similar mixture of washed human RBC and sheep plasma. The factor in sheep plasma was inactivated by heating at $70^{\circ} \mathrm{C}$ for $30 \mathrm{~min}$.

All six of the representative P-type-777 strains formed inhibitor on a medium composed of Gibco $\mathrm{CAB}$ and either human or sheep blood. One of the strains (A1013) also formed it on most batches of the Gibco medium in the absence of blood. On satisfactory batches of medium, strain A1013 caused a greater degree of acidification $(p \mathrm{H} c .6 .5)$ in the vicinity of bacterial growth than did other Ptype-777 strains $(p \mathrm{H} c .7 \cdot 0)$. This difference was seen to correlate with strong amylolytic activity by strain A1013, as shown by the disappearance of starch granules from the medium in the neighbourhood of the streak of bacterial growth.

\section{Role of streptococcal proteinase in inhibitory activity}

All six P-type-777 strains produced strong proteolysis when grown as stabs in CAB-skim-milk medium. Proteolytic activity against hide-powder 
Table I. Effect of composition of the medium and conditions of incubation on P-type-777 inhibitor production* by six strains of group-A streptococci

\begin{tabular}{ll|l}
\hline & Conditions & Inhibitory activity $\dagger$ \\
\hline Standard + & & +++ \\
Modified: & & \\
time $(\mathrm{h}):$ & 12 & ++ \\
& 48 & +++ \\
temperature $(\mathrm{C}):$ & 25 & - or + \\
& 37 & ++ or +++ \\
atmosphere: & anaerobic & +++ \\
basal medium: & $5 \%$ v/v $\mathrm{CO}_{2}$ in air & +++ \\
& Gibco Columbia Agar Base & +++ \\
blood supplement: & $\begin{array}{l}\text { Oxoid Blood Agar Base } \\
\text { none }\end{array}$ & - or + \\
& ovine in place of human & - \\
&
\end{tabular}

* Inhibition of all nine indicator stains.

$+-=$ No inhibition; $+=$ partial inhibition of some indicators, zone width $\leq 1 \mathrm{~cm} ;++=$ clear inhibition of most indicators; zone width $\geq 1 \mathrm{~cm}$; $+++=$ strong inhibition of all indicators, zone width $\geq 1 \mathrm{~cm}$.

Aerobic incubation on Difco Columbia Blood Agar Base plus human blood $5 \% \mathrm{v} / \mathrm{v}$ for $18 \mathrm{~h}$ at $32^{\circ} \mathrm{C}$.

azure was present in freeze-thaw extracts of lawn cultures of each of the representative strains on CAB medium plus human blood $5 \% \mathrm{v} / \mathrm{v}$ incubated in the standard P-typing conditions. In contrast, only strain A1013 produced significant levels of extractable proteinase when blood was omitted from the test medium.

To investigate further the possible relationship between streptococcal proteinase and P-type-777 activity, the production of each was assessed when cultures of the representative strains were grown in the standard conditions on Gibco CAB medium plus human blood $5 \% \mathrm{v} / \mathrm{v}$ with various additions (table II). The presence of calcium carbonate $0.5 \%$ w/v somewhat reduced local acidification of the medium without interfering with the production of either proteinase or P-type-777 activity, but definite alkalinisation by the addition of MOPS buffer abolished both proteinase production and inhibitory activity. Inclusion of glucose $0.5 \% \mathrm{w} / \mathrm{v}$ in the typing medium interfered with P-type- 777 inhibitor production. A similar effect could be achieved by addition of as little as $0.05 \% \mathrm{w} / \mathrm{v}$ of glucose (results not shown). Iodoacetic acid, lincomycin, trypan blue and Congo red, when present in sub-growthinhibitory concentrations, all appeared to suppress both proteinase and P-type- 777 activity. In the presence of these substances, some inhibition of indicator 17 persisted, giving rise to a P-typing pattern of 004 , but this was abolished by the addition of calcium carbonate. This inhibition seemed to be attributable to the particular sensitivity of $\mathrm{I} 7$ to an acidic $p \mathrm{H}$.

Incubation at a lower temperature $\left(25^{\circ} \mathrm{C}\right)$ interfered with inhibitor production (table I). Only minimal amounts of proteinase were produced by lawn cultures at this temperature. Previous studies (Hynes and Tagg, 1985b) indicated that the peptone 140 component of $\mathrm{CAB}$ medium was particularly important for proteinase production. In the present study we found that elimination of either peptone 140 or yeast extract rendered CAB medium unsuitable for the production of either P-type-777 activity or proteinase.

Proteinase did not seem to have direct inhibitory activity against any of the indicator strains. Activated streptococcal proteinase $(1 \mathrm{~g} / \mathrm{L})$ was not inhibitory to them when tested by the well-diffusion method on CAB medium. Moreover, the proteinase present in freeze-thaw extracts of $\mathrm{CAB}$ cultures of strain A1013 could be inactivated either by the addition of iodoacetic acid or by heating at $80^{\circ} \mathrm{C}$ for 30 min without significantly affecting the inhibitory activity of the preparations.

The relation of proteinase to the production of $\mathrm{P}$ type- 777 activity was investigated further by examining the properties of derivatives of strain M25 which had lost the ability to produce streptolysin S, proteinase or P-type-777 activity (table III). After nitrosoguanidine treatment of strain M25, four of 
Table II. Effect of additions to the test medium* on the P-typing pattern, $p \mathrm{H}$ and proteinase production by the six representative $\mathrm{P}$ type- 777 strains

\begin{tabular}{|c|c|c|c|}
\hline Additions & $\begin{array}{l}\text { P-typing } \\
\text { pattern } \dagger\end{array}$ & $\begin{array}{l}\text { Surface } p \mathrm{H} \\
\text { of medium } \ddagger\end{array}$ & Proteinase§ \\
\hline None & 777 & $6 \cdot 3$ & + \\
\hline Calcium carbonate $0.5 \% \mathrm{w} / \mathrm{v}$ & 777 & $6 \cdot 8$ & + \\
\hline MOPS $(0 \cdot 1 \mathrm{M}, p \mathrm{H} 7 \cdot 5)$ & 000 & $7 \cdot 3$ & - \\
\hline MOPS $(0 \cdot 1 \mathrm{M}, p \mathrm{H} 6.8)$ & 777 & $6 \cdot 6$ & + \\
\hline Glucose $0.5 \% \mathrm{w} / \mathrm{v}$ & 724 & $5 \cdot 5$ & - \\
\hline $\begin{array}{l}\text { Glucose } 0.5 \% \mathrm{w} / \mathrm{v} \text { plus calcium } \\
\text { carbonate } 0.5 \% \mathrm{w} / \mathrm{v}\end{array}$ & 204 & 6.0 & - \\
\hline Iodoacetic acid $(0.00005 \mathrm{M})$ & 004 & $6 \cdot 3$ & - \\
\hline $\begin{array}{l}\text { Iodoacetic acid }(0.00005 \mathrm{M}) \text { plus } \\
\text { calcium carbonate } 0.5 \% \mathrm{w} / \mathrm{v}\end{array}$ & 000 & $6 \cdot 8$ & - \\
\hline Lincomycin $(0 \cdot 1 \mathrm{mg} / \mathrm{L})$ & 004 & $6 \cdot 3$ & \\
\hline $\begin{array}{l}\text { Lincomycin }(0.1 \mathrm{mg} / \mathrm{L}) \text { plus } \\
\text { calcium carbonate } 0.5 \% \mathrm{w} / \mathrm{v}\end{array}$ & 000 & 6.8 & - \\
\hline Trypan blue or Congo red $(2 \mathrm{~g} / \mathrm{L})$ & 004 & $6 \cdot 3$ & - \\
\hline $\begin{array}{l}\text { Trypan blue or Congo red }(2 \mathrm{~g} / \mathrm{L}) \\
\text { plus calcium carbonate } 0.5 \% \mathrm{w} / \mathrm{v}\end{array}$ & 000 & $6 \cdot 8$ & - \\
\hline
\end{tabular}

* Gibco Columbia Agar Base plus human blood 5\% v/v; conditions of incubation as in table $I$.

$\dagger$ See Materials and methods.

$\ddagger$ After removal of the bacterial growth; mean values for the six strains.

$\S$ Hide-powder azure tested against freeze-thaw extracts from lawn cultures.

Table III. Phenotypic characters of strain M25 and some mutants of it obtained by means of nitrosoguanidine or transposon $\operatorname{Tn} 916$

\begin{tabular}{|c|c|c|c|c|}
\hline \multirow{3}{*}{$\begin{array}{l}\text { Strain } \\
\text { no. }\end{array}$} & \multicolumn{4}{|c|}{ Production of } \\
\hline & \multirow[b]{2}{*}{ streptolysin S } & \multicolumn{2}{|c|}{ proteinase } & \multirow{2}{*}{$\begin{array}{c}\text { P-type-777 } \\
\text { inhibition }\end{array}$} \\
\hline & & extracellular & cell-associated & \\
\hline M25 & + & + & + & + \\
\hline M25-3I & + & - & - & - \\
\hline M25-Tn3 & + & + & + & - \\
\hline M25-2H & - & + & + & + \\
\hline M25-Tn1 & - & + & + & + \\
\hline M25-1P & + & - & + & + \\
\hline
\end{tabular}

500 tested progeny clones were P-type-777-inhibitor negative; five of 4000 were streptolysin-S negative; seven of 500 were negative for extracellular proteinase (on Gibco CAB-plus-skim-milk medium) and six of these also were P-type-777-inhibitor-negative. The seventh (no. M25-1P) was inhibitor positive and was the only one of these strains found to be positive for cell-associated proteinase. The nitrosoguanidine-derived M25-3I was inhibitor negative and did not produce proteinase in the standard test conditions. Of 43 derivatives of M25 that appeared to have acquired Tn916, one (M25-Tn1) was streptolysin-S negative and nine (including M25-Tn3) were negative for P-type-777 activity, but were unchanged in streptolysin-S and proteinase activities. None of the streptolysin-S-negative derivatives of strain M25 showed concurrent loss of ability to produce P-type-777 activity. 
Partial purification and properties of the P-type-777 agent

All attempts to detect inhibitory activity either in the supernates or the cells of various liquid cultures failed; the media tested included Todd Hewitt Broth, Tryptic Soy Broth, Brain Heart Infusion, APT Broth and Gibco CAB medium (with the agar omitted).

Inhibitory activity was present in freeze-thaw extracts of lawn cultures of strain A1013 on Gibco $\mathrm{CAB}$ medium (without blood), which typically had titres (in $\mathrm{AU} / \mathrm{ml}$ ) of four against strain 11 , two against strains $\mathrm{I} 2$ and $\mathrm{I} 6$ and one against strain I7. Concentration of these extracts with ammonium sulphate generally gave material with a titre of 32 against strain II and with some activity against each of the other indicators except I9. When these concentrated preparations were fractionated on Sephadex G100 all the detectable activity was excluded from the gel, suggesting a mol. wt in excess of 100000 for the inhibitor in these conditions of production and purification. The inhibitor was not adsorbed to DEAE Sephadex at $p \mathrm{H} \mathrm{8.0.} \mathrm{It} \mathrm{was}$ bactericidal against each of the indicators tested (I1, I2, I4, I6 and I7) and also against the producer

Table IV. Stability of a crude preparation of P-type777 inhibitor* obtained from Gibco Columbia Agar Base cultures of strain A1013

\begin{tabular}{|c|c|}
\hline Treatment & Inhibitor titre $(\mathrm{AU} / \mathrm{ml})$ \\
\hline None & 32 \\
\hline 4 C, 4 weeks & 32 \\
\hline$-70^{\circ} \mathrm{C}, 24 \mathrm{~h}$ & 32 \\
\hline $80^{\circ} \mathrm{C}, 30 \mathrm{~min}$ & 32 \\
\hline Boiling. $30 \mathrm{~min}$ & 16 \\
\hline Boiling, $60 \mathrm{~min}$ & 4 \\
\hline$p H 3.0$ to $10 \cdot 0$ & 32 \\
\hline Sonic treatment, $60 \mathrm{~s}$ & 32 \\
\hline Millipore-membrane filtration & 32 \\
\hline Amylaset & 16 \\
\hline Lipase ${ }^{\dagger}$ & 16 \\
\hline$\alpha$-Chymotrypsin $\dagger$ & 16 \\
\hline Hyaluronidaset & 16 \\
\hline Streptococcal proteinase $\nmid$ & 16 \\
\hline Trypsint & 0 \\
\hline Protease $\mathrm{V}^{\dagger}$ & 0 \\
\hline Trypan blue $(2 \mathrm{~g} / \mathrm{L})$ & 0 \\
\hline Congo red $(2 g / L)$ & 0 \\
\hline
\end{tabular}

* Freeze-thaw extract of lawn cultures concentrated by precipitation with ammonium sulphate $(60 \%$ saturation).

+ At a concentration of $1 \mathrm{~g} / \mathrm{L}$ in $0.1 \mathrm{M}$ phosphate buffer $(\mathrm{pH}$ $7 \cdot 0$ ), and mixed with an equal volume of inhibitor preparation. Unchanged activity is therefore indicated by a titre of $16 \mathrm{AU} / \mathrm{ml}$. Incubation was at $37^{\circ} \mathrm{C}$ for $3 \mathrm{~h}$ followed by heating at $80 \mathrm{C}$ for $30 \mathrm{~min}$ to inactivate the enzyme. strain A1013, particularly when the indicators were in the logarithmic growth phase at the time of exposure. In experiments with I6, the viability of the treated cell suspensions decreased from $5 \times 10^{4} / \mathrm{ml}$ to $<1 \times 10^{3} / \mathrm{ml}$ within $1 \mathrm{~h}$ of exposure to the partially purified inhibitor. Suspensions of stationary-growth-phase cells gave a rate of kill less than half of that of logarithmic-growth-phase cells. There was no evidence of bacterilysis (decrease in optical density) accompanying the lethal activity of the inhibitor.

The inhibitor (table IV) was tolerant of extremes of $p \mathrm{H}$ and of temperature up to $80^{\circ} \mathrm{C}$ and was not affected by either sonic treatment or membrane filtration. It was sensitive to some proteases, but not apparently to streptococcal proteinase. The inhibitory activity was abolished by the dyes trypan blue and Congo red.

\section{Discussion}

The production by certain group-A streptococcal strains of a broad-spectrum inhibitor to which all nine of the indicators in our "fingerprinting" scheme are susceptible (P-type-777 activity) is associated with concurrent synthesis of a cell-associated proteinase. Proteinase production, however, is not the sole determinant of this inhibitory activity, because about $80 \%$ of group-A streptococci form proteinase (Hynes and Tagg, 1985b) whereas only about $10 \%$ are producers of P-type- 777 activity (Hynes and Tagg, 1985a).

Similar test conditions are unfavourable to the formation of proteinase and of the P-type-777 inhibitor. Elliott and Dole (1947) observed that streptococcal proteinase activity was reduced when cultures were grown at relatively low temperatures, and we found that there was little P-type-777 activity in cultures incubated at $25^{\circ} \mathrm{C}$. In the usual test conditions, detectable levels of the inhibitor are evident only quite late in the growth of the producer culture; and cells of the producer are susceptible to auto-inhibition only in the logarithmic phase of growth. This activity against self suggests a regulatory role in the growth cycle of the producer bacterium somewhat analogous to the relationship of some Streptococcus lactis strains to their autoinhibitory product, nisin (Hurst, 1981).

The composition of the medium has repeatedly been shown to affect critically the production of bacteriocin-like inhibitors (Tagg et al., 1976). In the current study, inhibitory activity developed only on media on which the test strains actively synthesised proteinase. The type of peptone in the medium greatly influences proteinase production (Elliott 
and Dole, 1947). Peptone 140 seems to be a component essential both for proteinase production (Hynes and Tagg, 1985b) and for P-type-777 activity in Gibco CAB medium. Streptococcal proteinase is produced as an inactive precursor, the formation of which is greatest in cultures achieving maximal growth at a slightly acidic $p \mathrm{H}$ (Elliott, 1950). Neither proteinase nor P-type-777 activity was detected in cultures maintained at an alkaline $p \mathrm{H}$ by inclusion of $0 \cdot 1 \mathrm{M}$ MOPS buffer at $p \mathrm{H} 7 \cdot 5$. Only one of six P-type-777 strains produced inhibitor on Gibco CAB in the absence of blood. This strain (A1013) had significantly higher amylolytic activity than the others; this may contribute to its being the only strain to effect a substantial drop in $p \mathrm{H}$ and a consequential production of proteinase on suitable batches of CAB.

The contribution of blood to the production of $\mathbf{P}$ type-777 inhibitor, and the reason why sheep blood sufficed for this on Gibco CAB but not on Difco $\mathrm{CBAB}$, are not fully understood. The production of another bacteriocin-like substance, streptococcin A-M57, by a proteinase-positive group-A streptococcal strain was also shown to be enhanced by the presence of blood (Simpson and Tagg, 1983), but in this case interference with proteinase formation by growth of the producer culture at an alkaline $p \mathrm{H}$ favoured production of the inhibitor. Plasma contains various substances able to interfere with proteinase activity (Travis and Salvesen, 1983) and the level of these seems to be significantly higher in sheep than in human plasma.

Various additions to the test medium prevented the production of both proteinase and P-type-777 inhibitor. Of these, iodoacetic acid is a known inhibitor of streptococcal proteinase (Elliott, 1945). Glucose interfered with both activities when added in concentrations as low as $0.05 \% \mathrm{w} / \mathrm{v}$ in what appears to be a catabolite-repression effect similar to that observed in cultures of group-B streptococci that produce the bacteriocin streptococcin B-74628 (Tagg et al., 1975). The lincosamine antibiotics, when present in sub-growth-inhibitory concentrations, inhibit the production of various group-Astreptococcal extracellular products (Gemmell and Abdul Amir, 1979). To this list can now be added streptococcal proteinase and P-type-777 activity. Trypan blue and Congo red are known to interfere with the haemolytic activity of streptolysin S(SLS) (Taketo and Taketo, 1982). When these were also found to prevent P-type-777 inhibitory activity, it raised the possibility that SLS might have a role in the production of inhibitory activity.

To help clarify the respective contributions of SLS and proteinase in inhibitor production, various mutated derivatives of the P-type-777 strain M25 were obtained after either nitrosoguanidine treatment or insertional inactivation with transposon Tn916. A role for SLS seemed unlikely since the SLS-negative derivatives were unaffected in their inhibitory activity. The inhibitor-negative strain M25-3I obtained after nitrosoguanidine treatment was also negative for proteinase production. In contrast, all nine of the transposon-derived inhibitor-negative isolates, represented by strain M25Tn3, appeared unaffected in their proteinase activity. These inhibitor-negative derivatives were frequently detected amongst the organisms that had acquired the transposon and it seems that either the structural or the control gene or genes for P-type777 inhibitor production may represent a "hot spot" site or sites for transposon insertion (Staringer, 1980). The gene or genes responsible for Ptype- 777 activity seem to be chromosomally located because, with a few exceptions, none of the producer strains has been found to contain plasmid DNA (Simpson and Tagg, 1984). Strain M25-1P at first appeared to present an anomaly because it was unaffected in inhibitor production in spite of being negative for proteinase when tested as a stab culture in CAB-skim-milk, but it exhibited cell-associated proteinase activity.

These observations suggest that proteinase is not directly responsible for P-type-777 inhibition. There is evidence, however, that it may have an indirect, though less broad-spectrum inhibitory effect (Hynes and Tagg, 1986). The proteolytic digestion of haemoglobin may lead to the production of toxic amounts of haematin, which may inhibit the indicators $\mathrm{I} 2$ and $\mathrm{I} 7$, so giving rise to the P-type pattern 204. This effect might contribute to the inhibitory action of P-type-777 strains when these are grown on blood-containing medium, but certainly cannot account for the inhibition of all nine indicators.

The properties of the P-type-777 inhibitor extracted from strain A1013 seem in general to be consistent with those of the rather loosely-defined group of antibiotic substances, the bacteriocins (Tagg et al., 1976). It appears to be at least partially protein in composition, as judged by its susceptibility to trypsin, and, from its behaviour on Sephadex G100, it seems to be of high mol. wt. Its action against the indicator bacteria is bactericidal, and this can be blocked by trypan blue or Congo red, in a similar way to the interference by these substances with haemolysis by SLS (Taketo and Taketo, 1982). P-type-777 strains are active against a wide range of gram-positive bacteria, particularly streptococci (Hynes and Tagg, 1985a). Amongst the gramnegative bacteria tested only a Bacteroides interme- 
dius strain was sensitive. Two other streptococcal bacteriocins, one produced by $S$. sanguis (Fujimura and Nakamura, 1979) and the other by $S$. mutans (Ikeda et al. . 1982) have been found to be active against Bacteroides strains, but not against other gram-negative bacteria.

The behaviour of the inhibitor on DEAE-Sephadex gels suggests that it is a cationic protein. Other antibiotics that appear to be cationic agents include the bacteriocin-like substance streptococcin AFF22 (Tagg et al., 1973), bacteriocin C3603 (Ikeda et al., 1982) and the peptide antibiotics nisin and Pep 5 (Bierbaum and Sahl, 1985). It has been reported by Vogt et al. (1983) that cationic extracell-

\section{REFERENCES}

Bierbaum G, Sahl H G 1985 Induction of autolysis of staphylococci by the basic peptide antibiotics Pep 5 and nisin and their influence on the activity of autolytic enzymes. Archives of Microbiology 141:249-254.

Cleary P P. Johnson Z, Wannamaker L 1975 Genetic instability of $M$ protein and serum opacity factor of group $A$ streptococci: evidence suggesting extrachromosomal control. Infection and Immunity 12:109-118.

Elliott S D 1945 A proteolytic enzyme produced by group A streptococci with special reference to its effect on the typespecific $M$ antigen. Journal of Experimental Medicine 81:573-592.

Elliott S D 1950 The crystallization and serological differentiation of a streptococcal proteinase and its precursor. Journal of Experimental Medicine 92:201-218.

Elliott S D. Dole V P 1947 An inactive precursor of streptococcal proteinase. Journal of Experimental Medicine 85:305-320.

Fujimura S. Nakamura T 1979 Sanguicin, a bacteriocin of oral Streptococcus sanguis. Antimicrobial Agents and Chemotherapy 16:262 -265.

Gemmell C G, Abdul Amir M K 1979 Effect of certain antibiotics on the formation of cellular and extracellular products by group A streptococci. In: Parker M T (ed) Pathogenic streptococci. Reedbooks Ltd, Chertsey, England. pp 67-68.

Hurst A 1981 Nisin. Advances in Applied Microbiology 27:85 123.

Hynes W L. Tagg J R $1985 a$ Production of broad-spectrum bacteriocin-like activity by group A streptococci of particular M-types. Zentralblatt für Bakteriologie Mikrobiologie und Hygiene A 259:155-164.

Hynes W L. Tagg J R $1985 b$ A simple plate assay for detection of group A streptococcus proteinase. Journal of Microbiological Methods 4:25-31.

Hynes W L, Tagg J R 1986 Role of proteinase in the formation of inhibitory levels of haematin by group A streptococcus cultures on blood-containing media. Journal of Clinical Microbiology 23:929-933.

Ikeda $\mathrm{T}$, Iwanami T, Hirasawa $\mathbf{M}$, Watanabe $\mathrm{C}$. McGhee J $\mathrm{M}$, Shiota T 1982 Purification and certain properties of a ular streptococcal antigens are frequently detected in renal biopsies from patients with acute poststreptococcal glomerulonephritis, and a role for these in the initiation of the disease has been proposed. Because bacteriocin-like inhibitorsparticularly the P-type-777 agent-occur very frequently in group-A streptococci of nephritogenic serotypes (Tagg, 1984), it is tempting to suggest that the cationic antigens detected in the affected kidneys might be similar to the P-type- 777 inhibitory agents.

This work was supported by grants from the Medical Research Council of New Zealand and the National Heart Foundation of New Zealand.

bacteriocin from Streptococcus mutans. Infection and Immunity 35:861-868.

Johnson D W, Tagg J R, Wannamaker L W 1979 Production of a bacteriocine-like substance by group-A streptococci of $\mathbf{M}$ type 4 and T-pattern 4. Journal of Medical Microbiology 12:413-427.

Nida K, Cleary P P 1983 Insertional inactivation of streptolysin S expression in Streptococcus pyogenes. Journal of Bacterio$\log y$ 155:1156-1161.

Simpson W J, Tagg J R 1983 M-type 57 group A streptococcus bacteriocin. Canadian Journal of Microbiology 29:1445 1451.

Simpson W J, Tagg J R 1984 Survey of the plasmid content of group A streptococci. FEMS Microbiology Letters 23:195199.

Starlinger P 1980 IS elements and transposons. Plasmid 3:241259

Tagg J R 1984 Production of bacteriocin-like inhibitors by group A streptococci of nephritogenic M types. Journal of Clinical Microbiology 19:884-887.

Tagg J R, Bannister L V 1979 “Fingerprinting” $\beta$-haemolytic streptococci by their production of and sensitivity to bacteriocine-like inhibitors. Journal of Medical Microbiology 12:397-411.

Tagg J R, Dajani A S, Wannamaker LW 1975 Bacteriocin of a group B streptococcus: partial purification and characterization. Antimicrobial Agents and Chemotherapy 7:764-772.

Tagg J R, Dajani A S, Wannamaker L W 1976 Bacteriocins of gram-positive bacteria. Bacteriological Reviews 40:722-756.

Tagg J R, Read R S D, McGiven A R 1973 Bacteriocin of a group A streptococcus: partial purification and properties. Antimicrobial Agents and Chemotherapy 4:214-221.

Taketo Y, Taketo A 1982 Effects of trypan blue and related compounds on production and activity of streptolysin S. Zeitschrift für Naturforschung 37C:385-389.

Travis J, Salvesen G S 1983 Human plasma proteinase inhibitors. Annual Review of Biochemistry 52:655-709.

Vogt A, Batsford S, Rodriguez-Iturbe B, Garcia R 1983 Cationic antigens in post-streptococcal glomerulonephritis. Clinical Nephrology 20:271-279. 